\title{
Human resources management practice, job satisfaction and affective organisational commitment relationships: The effects of ethnic similarity and difference
}

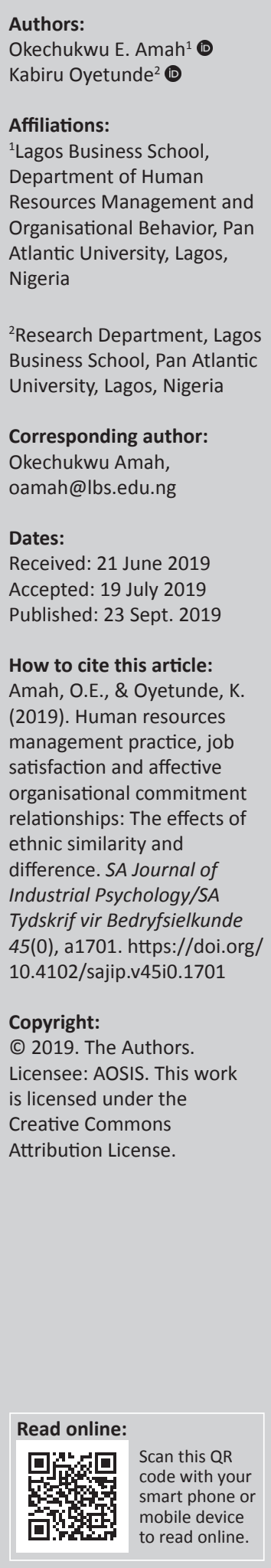

Orientation: The study explored how ethnicity affects the expected relationships among human resources management practice (HRMP), job satisfaction and affective organisational commitment.

Research purpose: To establish how ethnicity affects the interpretation of organisationally provided HRMP, and how this interpretation affects the relationships among the study variables.

Motivation for the study: Interest has moved from HRMP outcomes to how employees attribute meaning to existing HRMP. Hence, there is a need to study the variables that affect the attribution process and their effects on the effectiveness of HRMP.

Research approach/design and method: The study was quantitative and utilised crosssectional research design. Participants consisted of 450 employees from eight organisations in Nigeria.

Main findings: Results indicated that HRMP is positively related to job satisfaction and organisational commitment, and ethnicity is negatively related to job satisfaction and organisational commitment. Ethnicity moderated the relationships among HRMP, job satisfaction and organisational commitment.

Practical/managerial implications: Ethnicity affected the relationships among HRMP, job satisfaction and affective organisational commitment; hence, organisations may not be deriving the full anticipated benefits of HRMP. It was suggested that organisations should train managers to adopt positive behaviours that would enhance the management of ethnic diversity and reduce the negative effects of ethnicity.

Contribution/value-add: Ethnic similarity has cultural significance in Nigeria and is known to affect managers' and employees' behaviour and the sharing of organisational benefits in the workplace. However, studies involving its role in HRMP attribution process are lacking. Hence, this study makes a valuable contribution to how ethnicity affects attribution in HRMP studies.

Keywords: Job satisfaction; affective organisational commitment; human resources management practice; ethnicity; Nigeria.

\section{Introduction}

Organisations implement human resources management practice (HRMP) to improve the employees' knowledge, skills and motivation needed for the enhancement of organisational productivity and the achievement of sustainable competitive advantage. Hence, a well-articulated HRMP that is difficult to replicate is necessary for the success of any organisation. This is because such practices provide a competitive advantage to the organisation (Boxall, 1998; Mustafa, Richards, \& Ramos, 2013; Pahuja \& Dalal, 2014). Despite the contributions made by past studies in HRMP in developing and emerging economies (Anakwe, 2002; Anakwe, Igbaria, \& Anandarajan, 2000; Kamoche, 2000), more studies are still required to fully understand the role of HRMP in developing economies because of differences in culture and peculiarity of their economic environment (Anakwe et al., 2000; McGuaghey \& De Cieri, 1999; Pickler, Varma, Yu, Beenen, \& Davoudpour, 2014).

The direct effects of HRMP on individual and organisational outcomes have dominated past studies in HRMP (Huselid, 1995; Korff, Biemann, \& Voelpel, 2016; Mustafa et al., 2013). 
However, recent studies are directing attention to how employees attach meanings to HRMP and how such meanings affect the link between HRMP, performance and other important work outcomes (Messersmith, Patel, Lepak, \& Gould-Williams, 2011; Sanders \& Yang, 2015). Organisations establish HRMP with the expectation that the benefits employees derive will elicit positive work attitudes (Mustafa et al., 2013). However, the realisation of this expectation will depend on how employees attribute meanings to the established HRMP. This is an area of HRMP research that still has many unanswered questions in different cultures (Ostroff \& Bowen, 2015).

The current study explores the role of ethnic similarity in the process of attributing meaning to organisationally provided HRMP in a developing economy, and how this attribution affects the relationships among HRMP, job satisfaction and organisational commitment. The use of ethnic variable in HRM studies in sub-Saharan Africa is justified because of its prevalence in the cultural setting (Anakwe, 2002; Kamoche, 2000; Takyi-Asiedu, 1993). Ethnic groups in sub-Saharan Africa are oriented for survival and are positioned to maximise gains and minimise loss for people in the same ethnic groups. Hence, ethnic similarity affects the behaviour of leaders and employees in organisations in Africa and other areas (Nyambegera, 2002). Based on these, it is highly likely that employees from the same ethnic background as their manager will interpret and react to HR systems in the same way as their managers compared to employees from different ethnic groups and their supervisors. The outcome variables considered in this study are job satisfaction and affective organisational commitment (AOC). The selection of these variables is based on the social exchange theory that stipulates that the way employees are treated will give rise to their reciprocal behaviour that, in turn, will give rise to high or low commitment and satisfaction. Furthermore, these variables are known to affect the level of effort that employees are willing to give in achieving organisational goals.

The purpose of this study is to explore how ethnic similarity affects the relationship among HRMP, job satisfaction and AOC. Signalling and social exchange theories and norm of reciprocity were used to justify the various relationships in the model tested. The study makes two valuable contributions. The first is to confirm the universality of positive relationships among HRMP and work outcomes in the Nigerian context. The second is to add to the call to identify more intervening variables that define how HRMP affects employees' work outcomes, especially in a developing economy. Most studies on ethnicity and HRMP in subSaharan Africa have been mainly exploratory and conceptual (Anakwe, 2002; Egwa, 2016; Nyambegera, 2002). The current study quantitatively explored the role of ethnic similarity in the relationship among HRMP, job satisfaction and AOC in the workplace.

\section{Literature review}

Nigeria is in the sub-Saharan region of Africa. It is highly pluralistic in nature with over 250 sub-ethnic groups categorised into four major ethnic clusters. Nigeria is one of the most ethnically diverse countries in the world (Alesina, Devleeschauwer, Easterly, Kurlat, \& Wacziarg, 2013). From the 2016 report of the National Bureau of Statistics (NBS) Nigeria, the Nigerian economy is largely undiversified, consumptiondriven and heavily dependent on importation. Revenue from crude oil accounts for almost 95\% of the nation's foreign earnings. Earnings from high oil prices have largely not been felt by the general populace because of non-inclusive policies and practices. Current inflation and unemployment rates stand at $15 \%$ and $18 \%$, respectively (National Bureau of Statistics [NBS], 2016). Overall economic performance has been highly undermined by corruption, mismanagement, favouritism, nepotism, deplorable infrastructure and social amenities (Nwogu \& Ijirshar, 2016).

Following the amalgamation of the Northern and Southern Protectorates in 1914, Nigeria was divided into Northern, Western and Eastern regions, an action judged to be the foundation of primordial ethnic sentiments in the country. While the North remained united, the West and East felt that they were different ethnic groups, thus destroying the unity of the Southern Protectorate.

An ethnic group is a collection of people held together either by blood or ancestral relations (Umezinwa, 2012). The common blood and ancestor, whether real or imaginary, shared by people of the same ethnic group result in strong psychological connections and cohesion. Previous studies have theorised that ethnic similarity influences behaviour and attitude in multi-ethnic and diverse organisations (Bhopal, 2014; Parboteeah, Seriki, \& Hoegl, 2014), and is a source of gaining advantage in competing, conflicting and cooperating situations (Edewor, Aluko, \& Folarin, 2014). Within organisations, people carry a paraphernalia of values inherent in their ethnic group which is later mirrored in their work attitudes (Parboteeah et al., 2014). People of the same ethnic group are relatively at ease with each other and are prone to low levels of internal strife. However, in situations of ethnic differences, favouritism, lack of trust, low job satisfaction, organisational commitment and supervisor's support are rampant (Umezinwa, 2012).

Categorising ethnic groups in Nigeria is a function of several factors - shared language, myth of common origin, shared cultural attributes, geographical location and shared religious or spiritual beliefs (Ndubuisi, 2013). The Hausa or Fulani ethnic group domiciled in the Northern part of the country is the largest in terms of size and population. This accounts for its preponderance in the power structure and political offices holding. The Igbo ethnic group is a synthesis of smaller ethnic groups in the Eastern part of Nigeria. The Igbos are highly heterogeneous and decentralised in both political and social structures. They are entrepreneurial in nature, largely 
educated and highly industrious. The Yoruba ethnic group, who shares the Southern part of the country with the Igbos, is domiciled in the Western part of Nigeria. Like the Hausa or Fulani, the Yoruba are a homogenous socio-linguistic and cultural group. Their political and social structures are highly centralised, and they are known to be well educated and industrious.

The majority of Nigerians utilise their ethnic ties to achieve their aspirations in the area of employment, admission and political appointments (Uwaifo, 2016). They eschew official procedures and processes to do things in situations where they can establish ethnic and friendship ties (Uwaifo, 2016). Nigerians have been described as ethnic chauvinists (Adetiba \& Rahim, 2012; Nwofe, 2017; Olu-Olu, 2014). Umezinwa (2012) argued that ethnicity is a major problem militating against the development of the nation and that most Nigerians utilise ethnic identity to attract favours. The domination of certain ethnic groups in certain sectors of the economy has implications for justice and equitable sharing of resources. In most public and private organisations, ethnic considerations take precedence over competence and merit, and this has grave consequences for efficiency and productivity. This prevalent ethnic baggage is carried into the workplace and affects how individuals behave in the sharing of organisational benefits and assignments (Egwa, 2016).

\section{Theory building and hypotheses} Signalling theory

The theoretical foundation of this study is the signalling theory as adopted from the work of Connelly, Certo, Ireland, and Reutzel (2011). The signalling theory is concerned with how to minimise the information asymmetry when information is passed from one person to another. Individuals make decisions based on the information at their disposal (Connelly et al., 2011). The accuracy of the decisions made depends on the degree of information asymmetry. Information is passed with signals from the signaller to the receiver who observes and interprets the signal and sends feedback to the signaller. Signallers are mainly insiders with enough information about the organisation that is not available to the receiver (Bergh, Connelly, Ketchen, \& Shannon, 2014). As the receivers are not privy to the information available to the signaller, they use every available means to decode the signal received from the signaller. Signals from the signaller to receiver can either be positive or negative, intentional or unintentional. Bergh et al. (2014) argued that signallers are quick at passing positive signals intentionally to receivers, but do not send negative signals intentionally to reduce information asymmetry. The emphasis of the signalling theory is the deliberate issuing of positive information to elicit positive response from the receiver (Connelly et al., 2011). However, it is also possible that the signaller by actions and omissions could unintentionally send negative information to the receiver. For example, this study posits that positive information intended by managers to be conveyed by the provision of
HRMP can be blurred by unintended signals sent by ethnic differences.

An effective signaling process depends on the ability of the receiver to effectively scan the environment for signals (Taj, 2016). In making future decisions, receivers default to signals used in the past to make informed choices and decisions irrespective of the presence of other compelling signals (Karasek \& Bryant, 2015). Hence, receivers' interpretation is highly important, and they may interpret signals not as intended by the signaller (Bergh et al., 2014; Giones \& Miralles, 2015; Karasek \& Bryant, 2015; Taj, 2016). The current study is interested in how subordinates interpret the intended signal from HRMP using the unintended signal provided by ethnic similarity or difference between the manager and the subordinate. Previous HR studies have adopted signalling theory in examining the effects of HRMP on recruitment and employee online ratings (Chang \& Chin, 2018).

Managers in organisations use HRMP as signals to convey information to employees with the hope that employees will interpret the signals properly and reciprocate through improved job satisfaction and AOC. However, when employees experience information asymmetry occasioned by the signaller or signal, they use any of the signals perceived, whether intentional or not, to infer the motive behind the message (Bergh et al., 2014). It is therefore argued in this study that employees may utilise ethnic similarity between the manager and subordinate as a signal to infer the meaning and enactment of HRMP in the same way that entrepreneurs use technology usefulness to infer the value proposition of an idea (Giones \& Miralles, 2015). In this study, ethnic similarity is classified as unintentional signals sent by managers to employees along with intentional signals in the communication of HRMP. It is argued that employees whose ethnic groups differ from that of their managers who implement HRMP policies will likely take such ethnic difference as a signal in interpreting the motive behind the policy and respond on that basis. This will arise because of the prevalent situation in which ethnic similarity with the manager confers undue advantage on the employee (Nyambegera, 2002).

\section{Human resources management practice, job satisfaction and organisational commitment}

Globalisation has made international human resources management an issue that cannot be neglected by organisations who desire to operate in different cultures (Anakwe, 2002). Cross-cultural human resources management studies have identified that organisations must develop appropriate HRMPs, communicate and implement same to remain competitive across cultures (Kamoche, 2000). A gap in HRMP studies in developing economies is properly defining and understanding the link between HRMP, job satisfaction and AOC, while considering prevailing important local factors such as ethnic similarity or difference (Anakwe, 2002). The required strength of the relationships among HRMP, job satisfaction and AOC may not occur by just 
having HRMP in place. How employees perceive these policies is a major determinant of the strength of the relationships. Past studies have considered the expressed perception of employees (Kehoe \& Wright, 2010) and future time perspective (Korff et al., 2016). The current study used signalling theory to explore ethnic similarity or difference as possible boundary variables in the link between HRMP, job satisfaction and AOC.

Job satisfaction is described as the feelings of individuals about the different aspects of their job. The level of job satisfaction is attributed to both individual and organisational factors. Past studies have found mainly positive relationships between HRMP and job satisfaction (Boon, Den Hartog, Boselie, \& Paauwe, 2011; GouldWilliams, Mostafa, \& Bottomley, 2013). This relationship can be explained by the signalling theory, social exchange theory and norms of reciprocity. Those involved in social exchange relationship bring in resources and expect to receive resources in exchange through the process of reciprocity, for the relationship to endure. Human resources management practice that is beneficial to employees will send a positive signal that organisations value the contribution of employees. In the absence of any unintended signal, employees see this as positive social exchange currency that must be reciprocated (Rhoades \& Eisenberger, 2002). Thus, employees will develop a positive attitude to their job by way of high job satisfaction. Hence, the following hypothesis is postulated:

H1: Human resources management practice is positively related to employee job satisfaction.

Organisational commitment reflects an individual's level of identification and involvement with his organisation (Mowday, Steers, \& Porter, 1979). Organisational commitment has widely been studied by HR and organisational behaviour scholars because of its effect on the achievement of organisational goals and objectives. There are three forms of commitment that employees can have: affective, continuance and normative commitments (Meyer \& Allen, 1991). Meyer and Smith (2000) assert that the most effective form of organisational commitment is AOC, and this is the form used in the current study. Affective commitment is when employees are committed because they 'want to', because they see a high congruence between their values and those of the organisation. The relationship between HRMP and AOC can be explained by the signalling theory, social exchange theory and norm of reciprocity. The provision of HRMP by organisations sends positive signals of being valued by the organisation and is seen by employees as an exchange currency which must be reciprocated by way of identification and involvement with the organisation. Hence, a positive relationship will exist between HRMP and AOC. Past studies have established this positive relationship (see Gardner, Wright, \& Moynihan, 2011). Hence, the following hypothesis is postulated:

H2: Human resources management practice is positively related to AOC.

\section{The effects of ethnic difference}

Ethnic difference in organisations is a form of diversity that has been neglected in studies in the sub-Saharan region (Nyambegera, 2002). Ethnic diversity without inclusion can become a basis for poor management of human resources and subsequent poor performance in the organisation. According to Osaghae (1995, p. 11), ethnicity is defined as the employment and mobilisation of ethnic identity or differences to gain advantage in situations of competition, conflict or cooperation'. Ethnicity in Africa has a historical root, and prior to the colonisation of the continent, ethnic groups came together willingly and for mutual benefits, and were very supportive of each other (Laakso \& Olukoshi, 1996). However, during the colonial era, the colonial masters forcibly brought together diverse people who were antagonistic to one another and this created competition instead of the cooperation that characterised the precolonial era (Little, 2008). Despite the belief that ethnicity would disappear with time, the concept has persisted and has become more daring in postcolonial Africa (Roosens, 1989). However, management researchers in Africa have neglected this pervasive concept in organisational study; hence, a call was made by Kamoche (2000) that human resources managers should recognise ethnic differences and the demand it places on those in the workplace. Ethnicity is a source of attachment to people of similar ethnic origin and separation from others, and this impacts behaviour in diverse ethnic work environments. Ethnic identity provides biases that are reflected in negative work behaviour, exclusion of talented people from other ethnic groups and it also puts intense pressure on managers to act in favour of those with similar ethnic identity (Nyambegera, 2002). It is the basis for the 'subtle, nonphysical manifestation of interpersonal mistreatment' in organisations (Cortina, 2008, p. 55). It may be the basis for the distribution of rewards and may lead to talent wastage. For example, in Nigeria, ethnicity leads to prejudice, social discrimination and is the basis for appointments in most tertiary institutions (Egwa, 2016). Generally, employment in the sub-Saharan region depends on one's ethnic group and whom one knows. For example, Takyi-Asiedu (1993, p. 95) stated that 'there is a conviction that to give a job to a fellow tribesman is not nepotism, it is an obligation' because individuals are obligated to give preference to people from their ethnic origin who cannot find a job. This assertion is also supported by Nyambegera (2002). In summary, ethnicity plays out in all aspects of human resources management in organisations in the subSaharan region.

Studies have shown that the line manager's behaviour is a critical variable in the link between HRMP and employee outcomes (Sikora, Ferris, \& Van Iddekinge, 2015). There is also variability in how line managers interpret and implement existing organisation's HRMP. Past studies have put forward many reasons why this variability exists (Butler, Ferris, \& Napier, 1991). However, one aspect not covered by past studies and which is salient in the 


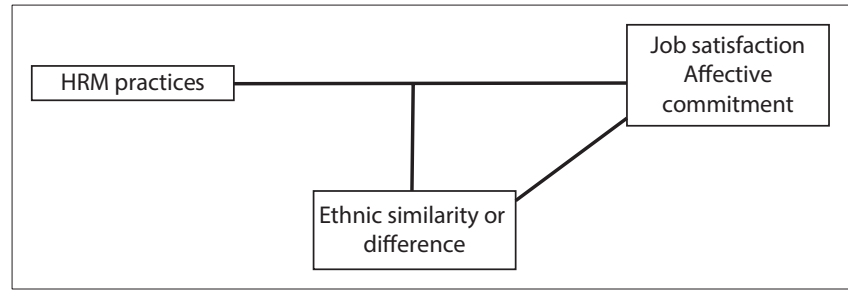

HRM, human resources management.

FIGURE 1: Hypothesised model.

environment of this study is the similarity or difference in the ethnic group of the line manager and subordinate. This is because ethnic similarity or difference has been established to affect how the benefits in organisation are interpreted and shared with employees (Anakwe, 2002; Takyi-Asiedu, 1993). As ethnicity forms a basis of rewards and ranking in organisations, ethnic similarity and difference will be a signal that will indicate to an employee how HRMP will be interpreted and implemented in the organisation. This will affect the employee's perception of the usefulness of HRMP and their work attitude reflected in job satisfaction and AOC. Thus, the following hypotheses are postulated:

H3a: Ethnic similarity is positively related to job satisfaction and $\mathrm{AOC}$.

H3b: Employees from the same ethnic group as their supervisor will have a stronger link between HRMP and job satisfaction than employees from different ethnic groups with their supervisor.

H3c: Employees from the same ethnic group as their supervisor will have stronger link between HRMP and AOC than employees from different ethnic groups with their supervisor.

The hypothesised model is shown in Figure 1.

\section{Research design Research approach}

The study is quantitative in nature and utilised cross-sectional data that were captured at a single point in time. Data were collected from eight companies using a questionnaire developed for the study. The participating organisations were drawn from different industries, and were randomly selected from the list of companies available to the researcher.

\section{Research method}

\section{Participants}

A random sample of participants was generated using the phone directory issued by the participating organisations. One thousand participants were targeted, but only 450 usable questionnaires were obtained (45\%). Five participants were dropped because they worked for expatriates. This was to ensure that all those who took part were Nigerians and worked with Nigerian managers. Out of the participants, $58 \%$ were male, $66 \%$ were married, and most of them have organisational tenure of between 6 and 10 years. Sixty per cent of the participants worked with managers from the same ethnic origin.

\section{Measurement instruments}

The first part of the questionnaire captured the demographic data of the participants, while the second part captured the variables used for the research. The choice of the demographic factors was based on the past studies establishing the variables that affected job satisfaction and organisational commitment (Amarasene, Ajward, \& Ahasanu Haque, 2015; Chirchir, 2016; Salami, 2008). Apart from ethnicity, all other study variables were measured with the five-point Likert scale from 1 = strongly disagree to $5=$ strongly agree .

\section{Ethnic similarity and difference}

This was measured with a single question which inquired if the participants reported to a manager in the same ethnic group. Two options of $1=$ Yes and $2=$ No were offered.

\section{Perceived human resources management practice}

Perceived HRMP was measured with 27 items taken from the work of Sun, Aryee, and Law (2007). The measure contains seven HRMPs listed as selective staffing (SS), extensive training (ET), internal mobility (IM), employment security (ES), job description (JD), result-oriented appraisal (ROA) and participation in decision. Exampleitems are 'Considerable importance is placed on the staffing process', 'Employees in customer contact jobs will normally go through training programs every few years', 'Employees have clear career paths in this organisation', 'Employees in this job can be expected to stay with this organisation for as long as they wish', 'This job has an up-to-date description', 'Performance is more often measured with objective quantifiable results' and 'Employees in this job are often asked by their supervisor to participate in decisions', respectively.

\section{Job satisfaction}

This was measured with five items taken from the work of Anderson, Coffey, and Byerly (2002). Example item is 'The work I do in my job is meaningful to me'.

\section{Affective organisational commitment}

This was captured with five items taken from the work of Kehoe and Wright (2010). Example item is 'I feel a strong sense of belonging to my organisation'.

\section{Control variables}

The control variables included gender ( $1=$ male, $2=$ female $)$, marital status $(1=$ single, $2=$ married $)$, tenure $(1=$ below 5 years, $2=6-10$ years, 3 = above 10 years $)$, job category $(1=$ junior to $4=$ managers $)$ and education $(1=$ primary school to $5=$ bachelor degree and above).

\section{Research procedure}

Each organisation nominated a contact person who worked with the researcher to identify the chosen participants and obtain their email addresses. The participants were sent emails requesting them to fill out the questionnaire sent to them in an envelope. There were instructions as to the 
purpose of the study and assurance of confidentiality of given information. They were told not to fill in any portion they did not want to fill in. No ethical issue was involved in the administration and gathering of data in this study.

\section{Data analysis}

\section{Preliminary analysis}

Data were analysed using the Statistical Package for Social Sciences (SPSS 23) and the Analysis of Moment of Structures (AMOS 23). The fit of the models in the AMOS analysis was established using the goodness of fit index (GFI), comparative fit index (CFI) and root mean standard error of approximation (RMSEA). For the GFI and CFI, an effective model must have at least a value of 0.9, while the RMSEA value must fall between 0.5 and 0.8 (Hu \& Bentler, 1999). Prior to analysis, the HRMP items were subjected to confirmatory factor analysis to ascertain the number of factors. As HRMP contained seven factors, seven-factor and one-factor models were tested. Results indicate that the seven-factor model was superior to the one-factor model with indices $\chi^{2}=187.39$; $d f=131 ; \chi^{2} / d f=1.430 ; \mathrm{GFI}=0.91 ; \mathrm{CFI}=0.97 ; \mathrm{RMSEA}=0.043$ (see Table 1).

\section{Common method analysis}

The questionnaire contained information that the data acquired would be used for research and presented in a format that would not identify participants. Participants were told to disregard any information they would not want to provide. In collecting the filled in questionnaires, envelopes were provided with the request to send directly to the researcher. These requests and information were aimed at minimising common method variance as recommended by Chang, Witteloostuijn, and Eden (2010). In addition to this, the study utilised three other methods to gauge the level of common method variance. Exploratory factor analysis using SPSS and stipulating non-rotation extracted nine factors in which the first factor extracted only $25 \%$ of the variance in the data compared to the total of $80 \%$ extracted by all the factors. This result indicated that common method variance was not an issue (Podsakoff \& Organ, 1986). Confirmatory factor analysis was carried out with one model containing 10 factors and the other constraining all the variables to load to a single factor. The 10-factor model has better indices of $\chi^{2}=573.56 ; d f=395 ; \chi^{2} / d f=1.452 ; \mathrm{GFI}=0.91 ; \mathrm{CFI}=0.96$; RMSEA $=0.045$ (see Table 2).

In the third method, a common factor was included in the 10 -factor model. The items loading on the common factor were constrained to be equal, while the variance of the factor was constrained to be 1 (Chang et al., 2010; Eichhorn, 2014). The constrained loading of the items on the common factor was 0.30 . Thus, the common method variance was $9 \%$ which is below the threshold point of 50\% (Chang et al., 2010; Eichhorn, 2014). The three tests jointly show that the level of the common method variance would not affect the results obtained in the current study.

\section{Construct, convergent and discriminant validity analysis}

Construct validity shows how items of a measure load on their respective factors. In Table 3, the loadings on all the variables are all above the cut-off point of 0.5 (Hair, Black, Babin, Anderson, \& Tatham, 2010). Convergent validity indicates agreement between items that measure the same variable. For this to be satisfied, all the loadings must exceed the cut-off point of 0.5 (Hair et al., 2010), Cronbach's reliability model must be above the cut-off point of 0.7 (Nunnally, 1978), and the

TABLE 1: Confirmatory factor analysis for the human resources management practices factors.

\begin{tabular}{lcccccc}
\hline Factor models & $\chi^{2}$ & $d f$ & $\Delta \chi^{2}$ & $\chi^{2} / d f$ & GFI & CFI \\
\hline One factor (all loaded on one factor) & 637.87 & 152 & - & 4.197 & 0.74 \\
Seven factors (all separate factors) & 187.39 & 131 & $450.48^{*}$ & 1.430 & 0.78 & 0.91 \\
\hline
\end{tabular}

$\mathrm{GFI}$, goodness of fit index; $\mathrm{CFI}$, comparative fit index; RMSEA, root mean standard error of approximation. $*, p<0.001$

TABLE 2: Confirmatory factor analysis for the study variables

\begin{tabular}{lcccccc}
\hline Model & $\chi^{2}$ & $d f$ & $\Delta \chi^{2}$ & $\chi^{2} / d f$ & GFI & RMSEA \\
\hline 1 Factor & 1995.42 & 431 & - & 4.630 & 0.50 & 0.134 \\
10 Factors & 573.56 & 395 & $1421.16^{*}$ & 1.452 & 0.91 & 0.96 \\
\hline
\end{tabular}

$\mathrm{GFI}$, goodness of fit index; $\mathrm{CFI}$, comparative fit index; RMSEA, root mean standard error of approximation. $*, p<0.001$.

TABLE 3: Convergent validity

\begin{tabular}{lccc}
\hline Variable & Range of item loadings on factors & Average variance extracted & Cronbach's alpha \\
\hline Selective staffing & $0.71-0.78$ & 0.75 & 0.89 \\
Training & $0.57-0.76$ & 0.85 & 0.83 \\
Internal mobility & $0.88-0.90$ & 0.81 & 0.73 \\
Employment security & $0.73-0.77$ & 0.75 & 0.76 \\
Result-oriented appraisal & $0.63-0.81$ & 0.76 & 0.71 \\
Participatory decision & $0.72-0.82$ & 0.76 & 0.85 \\
Job description & $0.77-0.81$ & 0.78 & 0.84 \\
Job satisfaction & $0.75-0.85$ & 0.71 & 0.72 \\
Organisational commitment & $0.72-0.80$ & 0.73 & 0.85 \\
\hline
\end{tabular}


average variance extracted by all factors must exceed the cutoff point of 0.5 (Hair et al., 2010). All these criteria were achieved as shown in Table 3, showing evidence of convergent validity. Koufteros, Vonderembse, and Doll (2002) recommended that the average variance extracted by each variable should be compared with the variance shared with other variables to ascertain discriminant validity. Each diagonal element in Table 4 is greater than its vertical and horizontal off-diagonal elements, showing evidence of discriminant validity.

\section{Results}

\section{Descriptive statistics and hypothesis testing}

The mean, standard deviation, reliability coefficient and correlation among study variables are in shown Table 5. Prior to calculating the interaction terms, the variables involved were centralised based on the work of Aikens and West (1991). Most of the HRMPs have positive significant relationships with job satisfaction and AOC. These results partially support Hypotheses 1 and 2, respectively. The hypotheses were tested with hierarchical multiple regression analysis in four stages. Stage 1 contains the control variables, stage 2 contains the HRMPs, stage 3 contains the ethnicity and stage 4 contains the interaction terms (see Table 6). After controlling, the control variables, it was found that job satisfaction has positive significant relationships with SS $(\beta=0.26, t=3.68, p<0.001)$,
$\operatorname{IM}(\beta=0.10, t=2.183, p<0.05), \mathrm{ES}(\beta=0.13, t=2.243, p<0.05)$, $\mathrm{JD}(\beta=0.12, t=2.114, p<0.05)$ and participatory decision (PD) $(\beta=0.38, t=6.310, p<0.001)$. Thus, Hypothesis 1 was partially supported. Affective organisational commitment has positive significant relationships with SS $(\beta=0.31, t=3.900, p<0.001)$ and $\operatorname{PD}(\beta=0.40, t=5.901, p<0.001)$. Hence, Hypothesis 2 was partially supported. The human resources practices accounted for $61 \%$ and $54 \%$ of the variance in job satisfaction and AOC, respectively. Ethnicity has a negative relationship with job satisfaction $(\beta=-0.18, t=-2.535, p<0.05)$ and with AOC $(\beta=-0.11, t=-1.998, p<0.05)$. Thus, employees from different ethnic groups to their supervisor have low job satisfaction and AOC. Hence, Hypothesis $3 a$ is supported.

Only the interaction between IM and ethnicity $(\beta=-0.20$, $t=-3.115, p<0.001)$ significantly predicted job satisfaction. Thus, Hypotheses $3 b$ is supported, while $3 c$ is not. The interaction term accounted for an additional $4 \%$ of the variance in job satisfaction.

To interpret the significant interaction terms, the method recommended by Aiken and West (1991) was adopted. Participants from the same ethnic group as their managers formed one group and those from different ethnic groups formed the second group. Regression analyses were run separately for the same and different ethnic groups.

TABLE 4: Discriminant validity.

\begin{tabular}{|c|c|c|c|c|c|c|c|c|c|}
\hline Study variables & 1 & 2 & 3 & 4 & 5 & 6 & 7 & 8 & 9 \\
\hline 1.Selective staffing & $0.75 \dagger$ & - & - & - & - & - & - & - & - \\
\hline 2. Training & 0.47 & $0.85 \dagger$ & - & - & - & - & - & - & - \\
\hline 3. Internal mobility & 0.01 & 0.01 & $0.81 \dagger$ & - & - & - & - & - & - \\
\hline 4. Employment security & 0.35 & 0.30 & 0.02 & $0.75 \dagger$ & - & - & - & - & - \\
\hline 5. Job description & 0.40 & 0.35 & 0.01 & 0.25 & $0.78 \dagger$ & - & - & - & - \\
\hline 6. Result-oriented appraisal & 0.40 & 0.46 & 0.01 & 0.27 & 0.31 & $0.76 \dagger$ & - & - & - \\
\hline 8. Job satisfaction & 0.50 & 0.32 & 0.03 & 0.30 & 0.36 & 0.37 & 0.51 & $0.71 \dagger$ & - \\
\hline 9. Affective organisational commitment & 0.45 & 0.29 & 0.01 & 0.22 & 0.30 & 0.30 & 0.48 & 0.01 & $0.73 \dagger$ \\
\hline
\end{tabular}

$\dagger$, The average variance extracted, and all other entries are squared correlation matrix.

TABLE 5: Means, standard deviations, reliability coefficient and correlations.

\begin{tabular}{|c|c|c|c|c|c|c|c|c|c|c|c|c|c|c|c|c|c|}
\hline Study variables & Mean & SD & 1 & 2 & 3 & 4 & 5 & 6 & 7 & 8 & 9 & 10 & 11 & 12 & 13 & 14 & 15 \\
\hline 1. Gender & - & - & - & - & - & - & - & - & - & - & - & - & - & - & - & - & - \\
\hline 2. Education & - & - & 0.01 & - & - & - & - & - & - & - & - & - & - & - & - & - & - \\
\hline 3. Marital status & - & - & $-0.19 * *$ & $0.17 *$ & - & - & - & - & - & - & - & - & - & - & - & - & - \\
\hline 4. Tenure & - & - & $-0.18 * *$ & $0.36 * *$ & $0.38 * *$ & - & - & - & - & - & - & - & - & - & - & - & - \\
\hline 5.Job category & - & - & $0.17 *$ & -0.14 & $-0.18 * *$ & 0.12 & - & - & - & - & - & - & - & - & - & - & - \\
\hline 6. Ethnicity & - & - & -0.03 & $0.15^{*}$ & 0.09 & $0.14 *$ & -0.05 & - & - & - & - & - & - & - & - & - & - \\
\hline 7. SS & 3.77 & 0.83 & 0.06 & -0.04 & 0.02 & 0.07 & $0.19 * *$ & 0.05 & $0.89 \dagger$ & - & - & - & - & - & - & - & - \\
\hline 8. Training & 3.69 & 0.94 & $0.17 *$ & 0.02 & 0.02 & 0.09 & -0.06 & 0.03 & $0.69 * *$ & $0.83 \dagger$ & - & - & - & - & - & - & - \\
\hline 9. IM & 3.13 & 10.06 & -0.05 & 0.06 & 0.12 & -0.03 & -0.11 & -0.02 & 0.01 & -0.03 & $0.76 \dagger$ & - & - & - & - & - & - \\
\hline 10. ES & 3.70 & 0.88 & 0.12 & 0.06 & -0.09 & -0.02 & -0.09 & 0.03 & $0.59 * *$ & $0.55^{* *}$ & $0.14 *$ & $0.71 \dagger$ & - & - & - & - & - \\
\hline 11. JD & 3.72 & 0.87 & 0.09 & -0.01 & 0.02 & 0.06 & -0.11 & 0.11 & $0.63 * *$ & $0.59 * *$ & 0.01 & $0.50 * *$ & $0.86 \dagger$ & - & - & - & - \\
\hline 12. ROA & 3.59 & 0.88 & 0.10 & 0.01 & -0.01 & -0.04 & $-0.19 * *$ & -0.07 & $0.63 * *$ & $0.68 * *$ & 0.10 & $0.52 * *$ & $0.56 * *$ & $0.85 \dagger$ & - & - & - \\
\hline 13. PD & 3.56 & 0.91 & 0.01 & -0.11 & 0.06 & 0.01 & $-0.21 * *$ & -0.08 & $0.62 * *$ & $0.48 * *$ & 0.05 & $0.46 * *$ & $0.53 * *$ & $0.61 * *$ & $0.84 \dagger$ & - & - \\
\hline 14. JS & 3.68 & 0.88 & 0.16 & -0.08 & 0.01 & 0.02 & $-0.16 * *$ & -0.08 & $0.71 * *$ & $0.57 * *$ & -0.05 & $0.55^{* *}$ & $0.60 * *$ & $0.61 * *$ & $0.72 * *$ & $0.92 \dagger$ & - \\
\hline
\end{tabular}

SS, selective staffing; IM, internal mobility; ES, employment security; JD, job description; ROA, result-oriented appraisal; PD, participatory decision; JS, job satisfaction; OC, organisational commitment; reliability coefficient on the diagonal.

Note: Gender coded: 1 = female and 2 = male; Ethnicity coded: 1 = same ethnicity as manager and 2 = different ethnicity than manager;

$\uparrow$, Reliability coefficient.

$*, p<0.05 ; * *, p<0.01$. 
TABLE 6: Moderated hierarchical regression analysis.

\begin{tabular}{|c|c|c|}
\hline \multirow{2}{*}{$\begin{array}{l}\text { Steps and independent } \\
\text { variables }\end{array}$} & \multicolumn{2}{|c|}{ Dependent variables } \\
\hline & JS & OC \\
\hline \multicolumn{3}{|l|}{ Step 1. Control variables } \\
\hline Gender & 0.11 & 0.07 \\
\hline Education & -0.13 & -0.09 \\
\hline Marital status & -0.01 & 0.07 \\
\hline Tenure & 0.07 & 0.02 \\
\hline Job category & $-0.18^{*}$ & $-0.19 *$ \\
\hline$R^{2}$ & $0.05 *$ & $0.05^{*}$ \\
\hline \multicolumn{3}{|l|}{ Step 2. Direct effects } \\
\hline SS & $0.26 * *$ & $0.31^{* *}$ \\
\hline Training & -0.01 & 0.07 \\
\hline IM & $0.10 *$ & -0.02 \\
\hline ES & $0.13 *$ & 0.03 \\
\hline$J \mathrm{D}$ & $0.12 *$ & 0.09 \\
\hline ROA & 0.10 & -0.01 \\
\hline PD & $0.38 * *$ & $0.40 * *$ \\
\hline$\Delta R^{2}$ & $0.61 * *$ & $0.54 * *$ \\
\hline \multicolumn{3}{|l|}{ Step 3. Direct effects } \\
\hline Ethnicity & $-0.18 *$ & $-0.11 *$ \\
\hline$\Delta R^{2}$ & $0.032 *$ & $0.012 *$ \\
\hline \multicolumn{3}{|c|}{ Step 4. Moderating variables } \\
\hline SS*Ethnicity & -0.10 & -0.18 \\
\hline Training*Ethnicity & -0.09 & 0.08 \\
\hline IM*Ethnicity & $0.20 * *$ & 0.08 \\
\hline ES*Ethnicity & -0.10 & -0.23 \\
\hline JD*Ethnicity & -0.05 & 0.07 \\
\hline ROA*Ethnicity & -0.08 & 0.09 \\
\hline PD*Ethnicity & -0.07 & 0.04 \\
\hline$\Delta R^{2}$ & $0.04 *$ & 0.03 \\
\hline
\end{tabular}

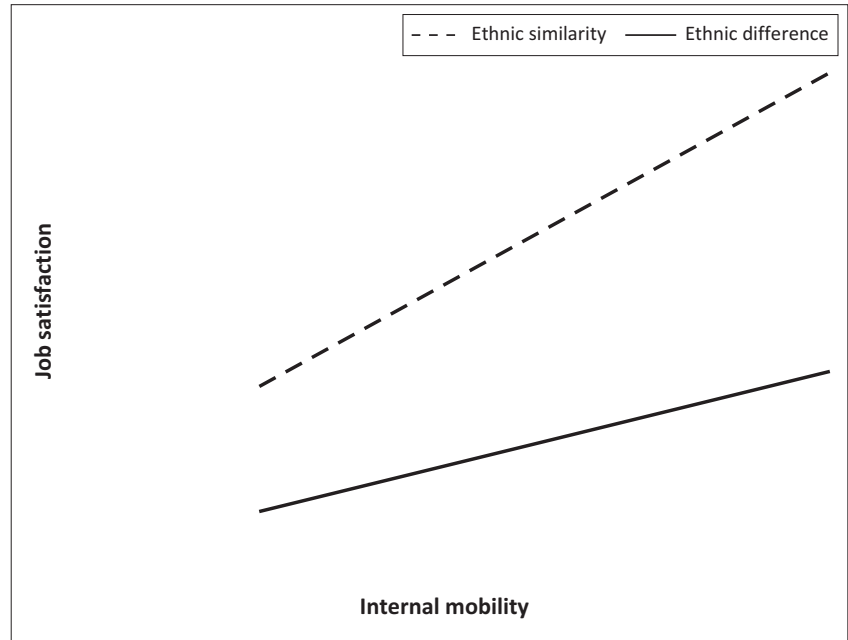

FIGURE 2: Interactive effect of ethnic similarity or difference on internal mobility and job satisfaction

The results indicate that the link between IM and job satisfaction was weaker for participants who work with supervisors from different ethnic groups than those who have similar ethnic group as their supervisor (see Figure 2).

\section{Discussions}

\section{Outline of results}

Drawing from the social exchange theory, norm of reciprocity and signalling theory, the study explored the nature of the relationships involving seven HRMPs, job satisfaction and
AOC, how employees decode the real purpose of HRMP using ethnicity, and whether the result of the decoding process affects the positive link between HRMP and employee job satisfaction and AOC. Although there is a consensus on the universality of the positive link between HRMP and employee work attitudes (Bowen \& Ostroff, 2004), there are suggestions that how employees give meaning to organisationally provided HRMP will differ because of contextual factors (Anakwe, 2002; Kamoche, 2000; Takyi-Asiedu, 1993). This has led to the call for more studies in emerging market cultures (Anakwe et al., 2000; McGaughey \& De Cieri, 1999). This study was carried out in a developing country, Nigeria, where ethnicity has a high influence on how employees and managers interpret work benefits and outcomes (Anakwe, 2002; Kamoche, 2000; Takyi-Asiedu, 1993).

Job satisfaction has positive relationships with five of the HRM practices, namely SS, IM, ES, JD and PD. Affective organisational commitment has positive relationships with two of the HRM practices, namely SS and PD. These results confirm the expectations of organisations that employees would see the provision of HRMP as evidence of organisational care and this should elicit a positive response from employees. These results also confirm the universality of the possible positive role of HRMPs when properly designed and implemented.

Participants from the same ethnic group as their supervisor have higher job satisfaction and AOC than those from different ethnic groups with their supervisor. Ethnicity is known to distort the relationship between employees and supervisors such that those who are from a similar ethnic group as their supervisors are treated better than those from different ethnic groups (Bhopal, 2014; Edewor et al., 2014; Parboteeah et al., 2014). Those from the same ethnic group are treated as in-group members, while others are treated as out-group members (Nyambegera, 2002). In-group members receive special benefits and treatments which are not available to out-group members (Urban, 2011). In-group members perceive this preferential treatment as social currency which they reciprocate by having high job satisfaction and high AOC.

The only significant interaction term is the one involving ethnicity and IM. The result indicates that for participants from the same ethnic group as their supervisor, the relationship between IM and job satisfaction was stronger than that from different ethnic groups as their supervisor. This means that the preferential treatment given to those from the same ethnic group as their supervisor signals that although IM may be provided by the organisation, the actual realisation would be tilted towards the in-group members (Apaolaza, Hartman, He, Barrutia, \& Echebarria, 2014; Urban, 2011). That IM interacted with ethnic similarity is not surprising because ethnic similarity plays out in the IM in organisations with those from similar ethnic groups as their supervisors getting most of the mobility (Egwa, 2016; TakyiAsiedu, 1993). 


\section{Implications for managers}

This work contributes to the debate on the universality of the positive link between HRMP and work attitudes, and how employees give meaning to organisationally provided HRMP across different cultures. Ethnic diversity is a form of diversity that must be encouraged in organisations. However, as demonstrated by the results obtained in this study, if it is not managed through inclusive principles, there are negative consequences. Having in-group and out-group members based on ethnic similarity and difference, respectively, is an indication of poor management of ethnic diversity. In subSaharan Africa, social identity variables play a major role in people's perception of being in-group or out-group members (Nyambegera, 2002). From the results obtained, social identity variables (in this study ethnic similarity and difference) acted as the signal that employees used to decode how organisationally provided HRMP would be administered. Such decoding affected their job satisfaction and AOC.

Organisations spend a huge part of their operating expenses providing HRMP yearly, with the assumption that employees will see the care inherent in such action and react positively through positive work attitudes (Korff et al., 2016). However, the results obtained indicate that this expectation may not be maximally achieved because of the ethnic background of managers and employees. The managerial implication from this study is that organisations are spending resources on HRMP but receiving little benefits by way of improved employee job satisfaction and AOC. In an environment in which preferential treatment of those from similar ethnic groups as their managers has been unconsciously imbibed and approved by managers, there is need to educate managers of the danger of such action in the management of diversity. Diversity is only beneficial to an organisation when managed through inclusive policies. The consequences of unmanaged diversity may be implicitly attributed to the entire organisation because when employees speak about these consequences, they may not restrict their comments to individual managers responsible for these actions but may speak as though the organisation approved the actions of its managers, who are perceived by employees as agents of the organisation. This has negative effects on the organisation when dealing with internal and external stakeholders. The existence of mismanagement of diversity can be inferred by the negative behaviour of managers. For example, a manager who associates with only people from his ethnic group selects only certain people into visible and high exposure jobs and uses languages not understood by all may be unintentionally creating an environment that can be perceived as rife in ethnicity. As stated by the Servant Leadership Institute, 'ever stop to think about the influence you have? The words you say, your body language and your actions all affect others'. To handle these situations, managers must be trained in the soft side of management, especially interpersonal relationships and the development of emotional intelligence. To hold managers responsible for diversity management in their units, organisations must include diversity management as a performance management criterion in evaluating managers.

\section{Limitations and directions for future research}

This study used cross-sectional research design; hence, common method variance cannot be ruled out. However, the three statistical analyses performed indicate that its level is low. Also because of the method of acquiring data, causality cannot be made. The participants came from private sector organisations in some industries; therefore, generalisation to public sector organisations should be cautiously made. However, the result is not expected to be different for the organisations in the public sector because the prevalence of these vices is more in such organisations (Nyambegera, 2002).

Future studies should extend the empirical study to cover organisations in the public sector and to more organisations and industries in the private sector. More variables that stratify people into groups should be considered as interaction variables to widen the number of social identity variables. More HRMPs should be considered in future studies.

\section{Conclusion}

Many authors have stated the pervasive nature of ethnicity in sub-Saharan Africa including Nigeria (Anakwe, 2002; Kamoche, 2000; Takyi-Asiedu, 1993), and that their existence is well known to both employees and managers. This study further established that employees use ethnicity to decode the real purpose of HRMP which ultimately affects their reactions to the provided HRMP. There is a general agreement within the Nigerian environment that ethnicity produces negative consequences in the environment (Egwa, 2016); however, the extent of the situation has not been adequately articulated.

\section{Acknowledgements Competing interests}

The authors confirm that they do not have any financial or personal relationships that may have influenced the writing of this article.

\section{Authors' contributions}

O.E.A. made the most contribution of conceptualising the project and driving data acquisition and analysis and wrote the entire project. K.O. is a research assistant who helped in the literature review.

\section{Funding Information}

This research received no specific grant from any funding agency in the public, commercial, or not-for-profit sectors. 


\section{Data availability statement}

Data sharing is not applicable to this article as no new data were created or analysed in this study.

\section{Disclaimer}

The views and opinions expressed in this article are those of the authors and do not necessarily reflect the official policy or position of any affiliated agency of the authors.

\section{References}

Adetiba, T. C., \& Rahim, A. (2012). Between ethnicity, nationality and development in Nigeria. International Journal of Development and Sustainability, 1(3), in Nigeria.

Aikens, L. S., \& West, S. G. (1991). Multiple regression: Testing and interpreting interactions. London: Sage.

Alesina, A., Devleeschauwer, A., Easterly, W., Kurlat, S., \& Wacziarg, R. (2013). Fractionalization. Journal of Economic Growth, 8(2), 155-194. https://doi. org/10.3386/w9411

Amarasene, T. S. M., Ajward, A. R., \& Ahasanu Haque, A. K. M. (2015). The effects of demographic factors on job satisfaction of university faculty members in Sri Lanka. International Journal of Academic Research and Reflections, 3(4), 89-106.

Anakwe, U. P. (2002). Human resources management practices in Nigeria: Challenges and insights. International Journal of Human Resources Management, 13 1042-1059. https://doi.org/10.1080/09585190210131285

Anakwe, U. P., Igbaria, M., \& Anandarajan, M. (2000). Managing practices across cultures: Role of support and technology usage. Journal of International Business Studies, 31(4), 653-666. https://doi.org/10.1057/palgrave.jibs.8490927

Anderson, S. E., Coffey, B. S., \& Byerly, R. T. (2002). Formal organizational initiatives and informal workplace practices: Links to work-family conflict and jobrelated outcomes. Journal of Management, 28(6), 787-810. https://doi. org/10.1177/014920630202800605

Apaolaza, V., Hartman, P., He, J., Barrutia, J. M., \& Echebarria, C. (2014). Choosing celebrity endorsers for advertisement campaigns in cosmopolitan China: Does their ethnicity matter? South African Journal of Business Management, 45(3), 45-55. https://doi.org/10.4102/sajbm.v45i3.130

Bergh, D. D., Connelly, B. L., Ketchen, D. J., \& Shannon, L. M. (2014). Signalling theory and equilibrium in strategic management research: An assessment and a research agenda. Journal of Management Studies, 51(8), 1334-1360. https://doi. research agenda. Journal
org/10.1111/joms.12097

Bhopal, R. S. (2014). Migration, ethnicity, race, and health in multicultural societies. Oxford: Oxford University Press.

Boon, C., Den Hartog, D. N., Boselie, P., \& Paauwe, J. (2011). The relationship between perceptions of HR practices and employee outcomes: Examining the role of person-organisation and person-job Fit. The International Journal of Human Resource Management, 22(1), 138-162. https://doi.org/10.1080/09585192.201 1.538978

Bowen, D. E., \& Ostroff, C. (2004). Understanding HRM-firm performance linkages: The role of the 'strength' of the HRM system. Academy of Management Review, 29(2), 203-221. https://doi.org/10.1016/S1053-4822(98)90005-5

Boxall, P. (1998). Achieving competitive advantage through human resources strategy: Towards a theory of industry dynamics. Human resources Management Review, 8(3), 265-288. https://doi.org/10.1016/S1053-4822(98)90005-5

Butler, J. E., Ferris, G. R., \& Napier, V. K. (1991). Strategy and human resources management. Cincinnati, $\mathrm{OH}$ : South-Western.

Chang, E., \& Chin, H. (2018). Signaling or experiencing: Commitment HRM effects on recruitment and employees' online ratings. Journal of Business Research, 84 175-185. https://doi.org/10.1016/j.jbusres.2017.11.002

Chang, S., Van Witteloostuijn, A., \& Eden, L. (2010). Common method variance in international business research. Journal of International Business Studies, 41 178-184. https://doi.org/10.1057/jibs.2009.88

Chirchir, R. (2016). Demographic factors and job satisfaction: A case of teachers in public primary school in Bomet, Kenya. Journal of Education and Practice, $7(13)$ 152-158.

Connelly, B. L., Certo, S. T., Ireland, R. D., \& Reutzel, C. R. (2011). Signaling theory: A review and assessment. Journal of Management, 37, 39-67. https://doi. org/10.1177/0149206310388419

Cortina, L. M. (2008). Unseen injustice: Incivility as a modern discrimination in organizations. Academy of Management Review, 33, 55-75. http://doi. org $/ 10.2307 / 20159376$

Edewor, P., Aluko, Y. A., \& Folarin, S. F. (2014). Managing ethnic and cultural diversity for national integration in Nigeria. Developing Country Studies, 4(6), 70-76.

Egwa, E. I. (2016). Influence of ethnicity on HRM in Nigerian tertiary institutions. African Educational Research Journal, 42, 85-90.

Eichhorn, B. R. (2014). Common method variance techniques. Internet Resources. Retrieved from: https://www.lexjansen.com/mwsug/2014/AA/MWSUG-2014AA11.pdf.
Gardner, T. M., Wright, P. M., \& Moynihan, L. M. (2011). The impact of motivation, empowerment, and skill-enhancing practices on aggregate voluntary turnover: The mediating effect of collective affective commitment. Personnel Psychology, 64(2), 315-350. https://doi.org/10.1111/j.1744-6570.2011.01212.x

Giones, F., \& Miralles, F. (2015). Do actions matter more than resources? A signalling theory perspective on the technology entrepreneurship process. Technology Innovation Management Review, 5(3), 39-45.

Gould-Williams, J. S., Mostafa, A. M. S., \& Bottomley, P. (2013). Public service motivation and employee outcomes in the Egyptian public sector: Testing the mediating effect of person organization fit. Journal of Public Administration Research and Theory, 25(2), 597-622. https://doi.org/ Administration Research
10.1093/jopart/mut053

Hair, J. F. Jr., Black, W. C., Babin, B. J., Anderson, R. E., \& Tatham, R. L. (2010). Multivariate data analysis (7th edn.). Upper Saddle River, NJ: Pearson PrenticeMall.

Hu, L. T., \& Bentler, P. M. (1999). Cutoff criteria for fit indexes in covariance structure analysis: Conventional criteria versus new alternatives. Structural Equation Modeling, 6, 1-55. https://doi.org/10.1080/10705519909540118

Huselid, M. A. (1995). The impact of human resource management practices on turnover, productivity, and corporate financial performance. Academy of Management Journal, 38(3), 635-672.

Kamoche, K. N. (2000). Sociological paradigms and human resources: An African context. Aldershot: Ashgate.

Karasek, R., \& Bryant, P. (2015). Signaling theory: Past, present, and future. Electronic Business Journal, 14(12), 550-558.

Kehoe, R. R., \& Wright, P. M. (2010). The impact of high-performance human resource practices on employees' attitudes and behaviours. Journal of Management, 39, 366-391. https://doi.org/10.1177/0149206310365901

Korff, J., Biemann, T., \& Voelpel, S. C. (2016). Human resource management systems and work attitudes: The mediating role of future time perspective. Journal of Organizational Behavior, 38, 45-67. https://doi.org/10.1002/job.2110

Koufteros, X. A., Vonderembse, M. A., \& Doll, W. J. (2002). Examining the competitive capabilities of manufacturing firms. Structural Equation Modeling, 9(2), 256-282. https://doi.org/10.1207/S15328007SEM0902_6

Laakso, L., \& Olukoshi, A.O. (1996). The crisis of the post-colonial Nation-State project in Africa. In A. Olukoshi, A. Adebayo \& L. Laakso (Eds.), pp. 7-39. Challenges to the Nation-State in Africa. Uppsala and Helsinki: The Nordic African Institute of Development Studies.

Little, P. D. (2008). Maasai identity on the periphery. American Anthropologist, 100 444-458. https://doi.org/10.1525/aa.1998.100.2.444

McGaughey, S. L., \& De Cieri, H. (1999). Reassessment of convergence and divergence dynamics: Implications for international HRM. The International Human Resources Management, 10, 235-250. https://doi.org/10.1080/ 095851999340530

Messersmith, J. G., Patel, P. C., Lepak, D. P., \& Gould-Williams, J. S. (2011). Unlocking the black box: Exploring the link between hygh-performance work systems and performance. Journal of Applied Psychology, 96, 1105-1118. https://doi. org/10.1037/a0024710

Meyer, J. P., \& Allen, N. J. (1991). A three-component conceptualization of organizational commitment. Human Resource Management Review, 1(1), 61-89. https://doi.org/10.1016/1053-4822(91)90011-Z

Mever, J. P. \& Smith, C. A. (2000). HRM practices and organizational commitment: Test of a mediation model. Canadian Journal of Administrative Sciences/Revue canadienne des sciences de l'administration, 17(4), 319-331. https://doi. org/10.1111/j.1936-4490.2000.tb00231.x

Mowday, R. T., Steers, R. M., \& Porter, L. W. (1979). The measurement of organizationa commitment. Journal of Vocational Behavior, 14(2), 224-247. https://doi. org/10.1016/0001-8791(79)90072-1

Mustafa, M., Richards, J. J., \& Ramos, H. M. (2013). High performance human resources practices and corporate entrepreneurship: The mediating effect of middle managers knowledge collecting and donating behaviour. Asian Academy of Management Journal, 18(2), 17-36.

National Bureau of Statistics (NBS), (2016). National unemployment statistics. Retrieved from: https://nigerianstat.gov.ng/\#unemp

Ndubuisi, F. N. (2013). Ethnic politics in Africa: The Nigerian example. In 5th European Conference on African Studies, Lisbon, Portugal, 27-29 June 2013 (pp. 1501-1513).

Nunnally, J. (1978). Psychometric theory. New York: McGraw-Hill.

Nyambegera, S. M. (2002). Ethnicity and human resources management practice in sub-Saharan Africa: The relevance of the managing of diversity discourse. The International Journal of Human Resources Management, 13, 1077-1090. https:// doi.org/10.1080/09585190210131302

Nwofe, E. S. (2017). Pro-Biafran activists and the call for a referendum: A sentiment analysis of 'Biafraexit' on twitter after UK's vote to leave the European Union. Journal of Ethnic and Cultural Studies, 4(1), 65-73.

Nwogu, J. A, \& ljirshar, V. U. (2016). The impact of corruption on economic growth and cultural values in Nigeria: A need for value re-orientation. International Journal of Economics \& Management Sciences, 6(1), 1-7. https://doi.org/10.4172/2162 6359.1000388

Olu-Olu, O. (2014). Ethnic identity and the crises of development in Nigeria. European Scientific Journal, 10(2), 216-229.

Osaghae, E. (1995). Structural adjustment and ethnicity in Nigeria. Research Report No. 98. Uppsala: The Nordic African Institute. 
Ostroff, C., \& Bowen, D. (2015). Reflections on the 2014 decade award: Is there strength in the construct of HR system strength. Academy of Management Review, 41, 196-214. https://doi.org/10.5465/amr.2015.0323

Pahuja, S., \& Dalal, R. C. (2014). Achieving competitive advantage through HR practices: A case study. Journal of Strategic Human Resource Management, 1(2), 35-43.

Parboteeah, K. P., Seriki, H. T., \& Hoegl, M. (2014). Ethnic diversity, corruption and ethical climates in sub-Saharan Africa: Recognizing the significance of human resource management. The International Journal of Human Resource Management, 25(7), 979-1001. https://doi.org/10.1080/09585192.2013.815251

Pickler, S., Varma, A., Yu, A., Beenen, G., \& Davoudpour, S. (2014). High performance work systems, cultures and gender diversity. Employee Relations, 36, 693-707. https://doi.org/10.1108/ER-11-2013-0165

Podsakoff, P. M., \& Organ, D. W. (1986). Self-reports in organizational research: Problems and prospects. Journal of Management, 12(4), 545-560. https://doi. org/10.1177/014920638601200408

Rhoades, L., \& Eisenberger, R. (2002). Perceived organizational support: A review of the literature. Journal of Applied Psychology, 87(4), 698. http://doi. org/10.1037/0021-9010.87.4.698

Roosens, E. E. (1989). Creating ethnicity: The process of ethnogenesis, Newbury, CA: Sage.

Salami, S. O. (2008). Demographic and psychological factors predicting organisational commitment among industrial workers. The Anthropologist, 10(1), 31-38. https:// doi.org/10.1080/09720073.2008.11891026
Sanders, K., \& Yang, H. (2015). The HRM process approach: The influence of employees' attribution to explain the HRM-performance relationship. Human Resource Management, 55(2), 201-217. https://doi.org/10.1002/hrm.21661

Sikora, D. M., Ferris, G. R., \& Van Iddekinge, C. H. (2015). Line manager implementation perceptions as a mediator of relations between high-performance work practices and employee outcomes. Journal of Applied Psychology, 100, 1908-1918. http:// doi.org/10.1037/apl0000024

Sun, L. Y., Aryee, S., \& Law, K. S. (2007). High-performance human resource practices, citizenship behavior, and organizational performance: A relational perspective. Academy of Management Journal, 50(3), 558-577. https://doi.org/10.5465/ amj.2007.25525821

Taj, S. A. (2016). Application of signaling theory in management research: Addressing major gaps in theory. European Management Journal, 34, 338-348. http://doi. org/10.1016/j.emj.2016.02.001

Takyi-Asiedu, S. (1993). Some socio-cultural forces retarding entrepreneurial activity in sub-Saharan Africa. Journal of Business Venturing, 8, 91-98. https://doi. org/10.1016/0883-9026(93)90013-U

Umezinwa, C. (2012). Ethnicity and Nigeria's underdevelopment. Ogirisi. A New Journal of African Studies, 9(1), 215-229.

Urban, B. (2011). Entrepreneurial networking differences: An ethnic in-group and outgroup analysis. SA Journal of Industrial Psychology/SA Tydskrif vir Bedryfsielkunde, 37(1), Art. \#826, 14. https://doi.org/10.4102/sajip.v37i1.826

Uwaifo, S. O. (2016). Ethnicity and development of political parties in Nigeria. Journa of Poverty, Investment and Development, 28, 1-9. 